\title{
A Prospective Randomised Trial of Nifedipine Versus Placebo in Preterm Labour
}

\author{
IFFAT ARA ${ }^{1}$, HASHINABANU ${ }^{2}$
}

\begin{abstract}
:
Objective: To evaluate nifedipine as a tocolytic agent and measure the side-effects

Methods : Prospective randomized study of 89 singleton pregnancies with preterm labour between 30-34 weeks of gestation. The capacity to delay delivery 48 h, 7 days, til 36 weeks were the outcome variable assessed.

Results: Nifedipine could successfully prolong delivery in about $82 \%$ of cases. There were fewer side-effects. Main side-effects were flushing and head-ache. Most of the patients complained of no side-effects.
\end{abstract}

Conclusion : Nifedipine is a well tolerated tocolytic drug with fewer side-effects.

Key word: Nifedipine, tocolysis, preterm labour

\section{Introduction:}

Preterm labour is defined as the presence of uterine contractions of sufficient frequency and intensity to effect progressive effacement and dilatation prior to term gestation. Preterm labour and preterm births occur in approximately $12 \%$ of all pregnancies and is the leading cause of neonatal death in the United States as well in the developing countries ${ }^{1}$. In addition, preterm birth accounts for $70 \%$ of neonatal morbidity, and mortality, and health care spent on the neonate ${ }^{2}$.

Despite the current use of material, effort and money in perinatal medical technology neonatal mortality rates continue to remain high. Implementation of effective risk identification, strategies and programms for the prevention of preterm labour may lead to successful reduction of perinatal morbidity and mortality associated with prematurity. This in turn requires both an improved understanding of the psychosocial risk factors, etiology, mechanisms of preterm labour, and programmes for accurate identification of pregnant women at risk of premature labour and delivery ${ }^{3}$.

Until an etiological treatment is found for preterm labour, treatment is based on preventing unwanted uterine contractions. Several therapeutic attempts have been made to inhibit uterine activity such as ethanol, prostaglandin synthetase inhibitors, magnesium sulphate, ritordine and beta-sympathomimetics. The side effects as well as the limited success have stimulated the investigators to search for new drugs such as oxytocin antagonists, calcium channel openers and calcium channel blockers ${ }^{4}$.

Nifedipine, a calcium channel blocking agent inhibits smooth muscle contraction by impeding the flow of calcium across the muscle cell membrane.

The aim of the study was to evaluate the tocolytic efficacy of nifedipine in preventing preterm labour and to evaluate the side effects.

\section{Material and Methods}

The study was conducted in the Institute of Child \& Mother Health Matuail Dhaka \& a private hospital, between January 2005 till December 2008. Eighty nine patients presenting with preterm labour between 30 34 weeks with singleton pregnancy and intact membrane were included in the study. Preterm labour was diagnosed by minimum of four contractions in 30 min. and cervical dilatation less than $3 \mathrm{~cm}$. The subjects who met the inclusion criteria were randomized to receive either oral nifedipine or placebo by lottery method. There were 45 patients in the nifedipine group and 44 in the placebo group. Written consent was obtained from them. Women were considered to enroll for the study if preterm labour occurred between 30 and 34 weeks of singleton pregnancy and intact membrane. Exclusion criteria

1. Associate Professor, Dhaka Medical College

2. Assistant professor, Institute of Child and Mother Health 
were cervical dilatation more than $3 \mathrm{~cm}$, evidence of maternal infection, vaginal bleeding, severe PE, fetal growth restriction and oligohydramnios. Evaluation for the presence of genital infection was done by WBC count and some selected clinical parameters like uterine tenderness, maternal temperature, and foul smelling vaginal discharge. High vaginal swab was sent for routine examination and culture. Blood pressure monitoring was done regularly.

Nifedipine tocolysis was started with a loading dose of $30 \mathrm{mg}$ ( $20 \mathrm{mg}$ oral and $10 \mathrm{mg}$ sublingually) followed by 20 mg every 4-6 hourly depending on the uterine activity. If uterine contraction was not subsided within 12 hrs of starting the treatment the case was considered as treatment failure. Subsidence of contraction was defined by absence of subjective feelings of pain by the patient. To measure the efficacy of this drug to postpone delivery three indicators were used- delay of labour for $48 \mathrm{hrs}$, for 7 days, continuation of pregnancy till 36 weeks. Side effects like head-ache, dizziness, muscle cramps, nausea and low blood pressure were evaluated. The patients remained at bed rest for 72 hours. After tocolysis the patients were discharged from the hospital after seven days with advice to come for check-up every weekly.
Because the samples were not uniformly distributed, they were analyzed using non-parametric statistics Kreskas -Wallis $U$-tests. Significance was set at 0.05 . Data were expressed as mean \pm standard error of the mean (S.E.M). Effect of tool sets was calculated by chi-square test. Significance was set at 0.05.

\section{Results}

The characteristics of both groups are detailed in table 1. The groups were comparable in maternal age, parity, gestational age and Bishop scoring .

Thirty five women (77.8\%) assigned to nifedipine had successful tocolysis (delay of delivery $>48 \mathrm{hrs}$ ). This group remained un-delivered till at the end of seven days. The end point of 36 weeks of pregnancy could be achieved by 2 patients (4.4\%). Failure of tocolysis was diagnosed in 8 patients (17.8\%). Among the placebo group tocolysis for more than 48 hours could be achieved by only $5(11.4 \%)$. The rest of the patients (88.6\%) delivered within 12 hours.

Maternal side- effects were less in the nifedipine group. Twenty patients (44.7\%) had no side-effects. Eighteen patients (40\%) complained of flushing and rest seven patients (15.6\%) had head-ache and vertigo. The placebo group had no side-effects.

Table-I

Characteristics of the study population

\begin{tabular}{lccc}
\hline Variable & Nifedipine $\mathrm{N}=45$ & Placebo N=44 & p-value \\
\hline Age (Years) & $21 \pm 2.0$ & $22 \pm 1.5$ & NS \\
Primipara & $17 \pm 2.0$ & $15 \pm 2.0$ & $\mathrm{NS}$ \\
Prenatal visit & $7.5 \pm 1.4$ & $8.4 \pm 1.2$ & $\mathrm{NS}$ \\
H/O previous preterm labor & 3 & 1 & $\mathrm{NS}$ \\
Gestational age & $32.5 \pm 0.5$ & $32.6 \pm 1.5$ & $\mathrm{NS}$ \\
Bishop score at diagnosis & $2.9 \pm 0.94$ & $2.6 \pm 0.89$ & $\mathrm{NS}$ \\
\hline
\end{tabular}

Table-II

Prolongation of pregnancy (chi-square test)

\begin{tabular}{lcccc}
\hline & \multicolumn{2}{c}{ Nifedipine $\mathrm{N}=45$} & \multicolumn{2}{c}{ Placebo $\mathrm{N}=44$} \\
\cline { 2 - 5 } & $\mathrm{n}$ & $\%$ & 05 & $\mathrm{n}$ \\
\hline$>$ 48 hours - 7 days & 35 & 77.8 & 00 & 11.4 \\
Upto 36 weeks & 02 & 4.4 & 39 & 00 \\
Failure & 08 & 17.8 & 88.6 \\
\hline
\end{tabular}

$X^{2}=44.8$ which is more than the table value 3.84 so $p$ value is, $<.05$ 


\section{Discussion:}

It is well documented that the efficacy of nifedipine in suppressing preterm labour appears to be as good as and possibly better than, ritrodine and terbutaline. It also appears equivalent in its ability to prolong pregnancy ${ }^{5,6}$.

One study has compared nifedipine with magnesium sulphate and ritrodine ${ }^{5,6}$. They found tocolytic activity more or less same but side-effects were more in the ritrodine group. Papatsoninis et $\mathrm{al}^{7}$ randomized 185 women in preterm labour between 20 and 33 weeks to receive either intravenous ritrodine or oral nifedipine. The authors defined preterm labour as either one contraction or more every ten minutes. The dosage regimen was $10 \mathrm{mg}$ nifedipine every 15 minutes for the first hour until contraction stopped (to a maximum of $40 \mathrm{mg}$ ). Then a daily dose of slow release nifedipine 60-160 mg depending on the amount needed in the first hour. Significantly fewer number of women taking nifedipine delivered within 24 hours, within 48 hours and within 7 days in comparison to ritrodrine. Twelve women discontinued ritrodine because of side-effects, compared with none taking nifedipine. Fetal outcome was similar, with no difference in Apgar scores or in arterial or venous $\mathrm{pH}$ measurement at birth. There were significantly fewer admissions to the neonatal intensive care unit in the nifedipine group.

Kupferminc ${ }^{8}$ undertook a randomized trial including 71 women to compare nifedipine and ritrodine, and showed a similar prolongation of pregnancy for 48 hours, 7 days and until 36 weeks. Nifedipine was administered in an initial dose of $30 \mathrm{mg}$ followed by further $20 \mathrm{mg} 90$ minutes later if uterine contractions persisted. A maintenance dose of nifedipine was then given orally every 8 hours. Eleven women with twin pregnancies were included in this trial; of the six that received nifedipine three delivered after 36 weeks gestation, compared to three of the five women who received ritrodine. These results have shown comparable efficacy of nifedipine and ritrodine in suppressing preterm delivery.

Glock amd Morales ${ }^{9}$ found nifedipine to be as effective as magnesium sulphate in delaying delivery for 48 hours, with success rate $92 \%$ and $93 \%$ respectively. McLaughin et $\mathrm{al}^{10}$ showed these two drugs had similar efficacy in prolonging pregnancy and preventing birth before 37 weeks of gestation.

A major advantage noted in these studies is the reduced amount of maternal side effects reported with the use of nifedipine than with ritrodine or terbutaline.A systematic review in the Cochrane Library, ${ }^{11}$ comparing nifedipine and the beta-sympathmimetic drugs showed that nifedipine reduces the number of deliveries of newborn infants weighing less than $2500 \mathrm{gm}$, but the number of infants admitted to the neonatal intensive care unit was increased. There was no difference in the stillbirth or neonatal death rate.

The tocolytic efficacy of nifedipine in the present study is $82 \%$, which is statistically significant and is comparable with ritrodine, terbutaline or magnesium sulphate as shown in other studies ${ }^{7-9}$. Since some of the drugs like terbutaline are not available and facilities for ICU support are needed for terbutaline and ritrodine, so alternatively nifidepine can be recommended as a tocolytic agent as it has fewer side effects. The dosage used in the present study was similar to the dose used in Kupfermins et al ${ }^{8}$. It was seen that successful tocolysis can be achieved with the given dosage.

The concern for side-effects is an important factor for the choice of some of the tocolytic drugs like betamimetic. The various side effects in ritordine treated group were tremor, palpitation, and nervousness and less important headache and chest pain or dizziness ${ }^{9}$. In the present study side effects of nifedipine were less frequent and severe flushes and headache being the most discomforting problem. Similar side effects for nifedipine were also reported by other authors ${ }^{12}$. The present study provides data supporting nifedipine as a safe tocolytic agent, better tolerated and with less maternal side-effects. Though the series is small but still multicenter trial can be done for evaluating the tocolytic efficacy of nifedipne.

\section{References:}

1. Main DM, Main EK. Preterm birth. In: Gabbe Sh, Niebyl JR, Simpson JL, editors. Obstetrics - normal and problem pregnancies. New York: Churchill Living-stone, 1991: 829-880.

2. ACOG practice bulletin. Management of preterm labour. Int J Gynaecol Obstet 2003;43 (1): 12735.

3. American College of Obstetricians and Gynecologists. ACOG Practice Bulletin. Assessment of risk factors preterm birth. Clinical management guideline for obstetricians and gynecologists. Obstet Gynecol 2001; 98(4): 709-16

4. MorrisonJJ, Ashford MLJ, Khan RN et al. The effects of potassium channel openers on isolated 
pregnant human myometrium before and after the onset of labour: potential for tocolysis. Am J Obstet Gynecol 1993 ;169:1277-1285.

5. Gock JL,MoralesWJ.Efficacy and safety of nifedipine versus magnesium sulphate in the management of preterm labor:a randomized study. Am J Obstet Gynecol 1993; 169:960-964.

6. Read MD,Wellby DE. The use of a calcium antagonist (Nifedipine) to suppress preterm labour. Br J Obstet gynaecol 1986; 93: 933-937.

7. Papatsonis DNM,van Geijn HP, Ader HJ,LandeFM,Bleker OP,Dekker GA. Nifedipine and ritrodine in the management of prteterm labour:a randoimised multicenter trial. Obstet Gynecol 1997; 2 : 230-234.

8. Kupferminc M, Lessing JB, Yaron Y,Peyser MR. Nifodine for suppression of preterm labor . Br J Obstet Gynaecol 1993; 100:1090-1094.

9. Glock JL, MoralesWJ. Efficacy and safety of nifedipine versus magnesium sulphate in the management of preterm labor:a randomized study. Am J Obstet Gynecol1993; 169 : 960964.

10. McLaughlin BN, Martin WE, vs betamimetics Roberts WL, Wiser JC. Comparison of magnesium and nifedipine for primary tocolysis and idiopathic preterm labour. Am J Obstet Gynecol 1992; 166:446.

11. Keirse MJNC. Calcium antagonists vs betamimetics in preterm labour. In : Neilson JP, Crowther C, Hodnett ED, Hofmeyr GJ, Keirse MJNC, editors. Pregnancy and Childbirth Module of the Cochrane Database of Systematic Reviews. Oxford: Update Software, Issue 2, 1995.

12. Weerakul W, Chittacharoen A, Suthutvoravut S. Nifedipine versus terbutaline in management of preterm labour. Obstet Gynaecol 2002; 76(3): 311-313 